\title{
Morphological Analysis of Particles Formed by Aeolian Abrasion in Dune Sands
}

\author{
R. Morales-Ochoa ${ }^{1}$, F. A. Paz-Moreno ${ }^{2}$, E. Ortiz-Rascón ${ }^{3}$, R. C. Carrillo-Torres ${ }^{1}$ and M. E. Álvarez- \\ Ramos $^{1}$ \\ ${ }^{1}$ Departamento de Física. Universidad de Sonora (UNISON), Hermosillo, Sonora, México. \\ 2. Departamento de Geología. Universidad de Sonora (UNISON), Hermosillo, Sonora, México. \\ 3. CONACYT - Departamento de Física, Universidad de Sonora (UNISON), Hermosillo, Sonora, \\ México.
}

Studies have been reported in which the content of nanometric particles in aeolian sands in austral deserts is analyzed [1]. The study of these subject within the perspective of nanotechnology is a methodological challenge, in which the employment of careful techniques that allow to concentrate these nanomaterials without modifying their natural characteristics of origin, starting from the principle that we are dealing with nanominerals $[2,3]$ of a certain compositional complexity of multicomponent type, and not of simple elementary systems.

The present work consists of presenting a methodology with which it is possible to obtain nano-sized particles separated by decantation, from sands with an average size of $200 \mu \mathrm{m}$ subjected to natural erosion processes collected in the sand dunes of the Biosphere of Pinacate and Desert of Altar, in the State of Sonora, Mexico [4]. Previous studies of these areas in the region are geological, focused on aspects of origin and provenance of sands [4]; processes of dune formation [5]; fine geochemistry and morphometry of the sands with genetic approach.

Samples of different dunes were collected in the area, which were mixed to obtain a representative sample for study, and analyzed with Leica DM2500P Petrograhic Microscope. Figure 1 shows a sample of sand as extracted from the dunes. Part of this sample was mixed with deionized water, stirring it for 20 minutes, after which it was allowed to stand still for some time, and samples of the mixture were taken at different times, which were subjected to the later analyzes.

Subsequently, samples were analyzed by the techniques of Dynamic Light Scattering (DLS) with Malvern ZetaSizer Nano ZS90, and Scanning Electron Microscopy (SEM) coupled with Energy Dispersive X-Ray Spectroscopy (EDS) with FE-SEM JEOL JSM-7800F. Figures 2 and 3 show the morphology and size of fine particles, along with elemental chemistry.

\section{References:}

[1] M. Baddock et al, Geoch. Geoph. \& Geos. 14(9) (2013), p. 3720.

[2] M.F. Jr. Hochella et al, Science 319 (2008), p. 1631.

[3] M.F. Jr. Hochella, Elements 4(6) (2008), p. 373.

[4] Solís Limón, M.F. (2003) "Caracterización y procedencia de las dunas que bordean al Campo volcánico El Pinacate, Sonora, México.", Maestría en Ciencias Geología, Depto. de Geología UNISON, (2003), $157 \mathrm{pp}$.

[5] Solís Limón, M.F. \& Paz Moreno, F.A., Reunión Anual de la Unión Geofísica Mexicana A.C. 25(1) (2005), p. 164. 


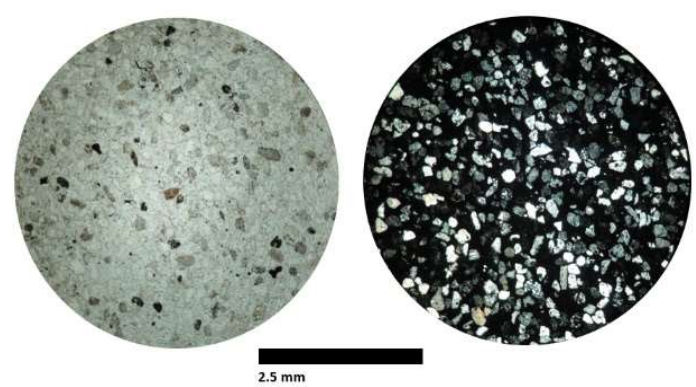

Figure 1. Image of dune sand particles using petrographic microscope.
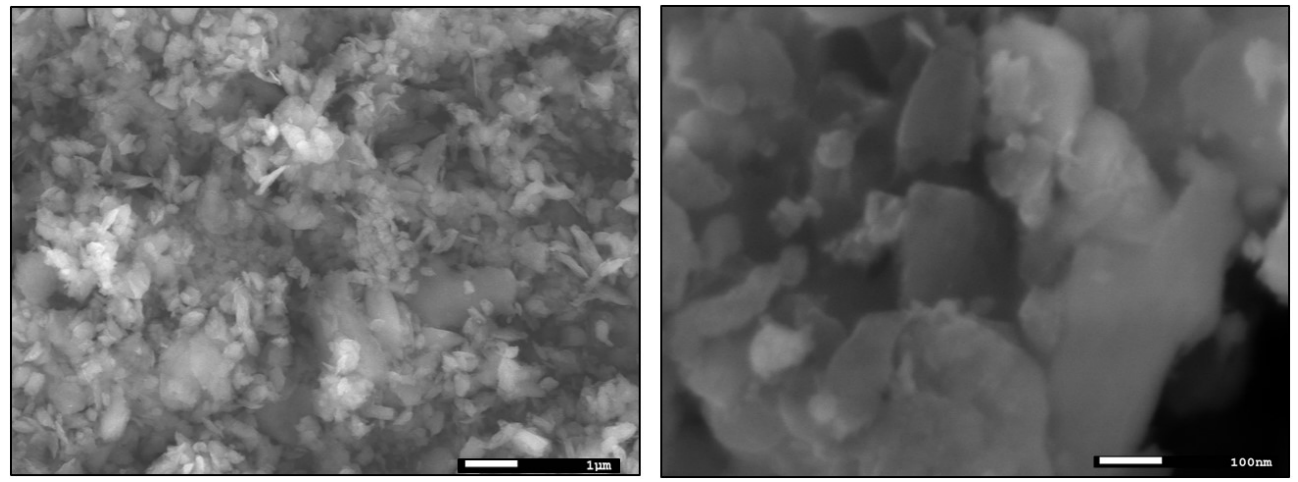

Figure 2. Morphology of particles obtained after stir and decantation.

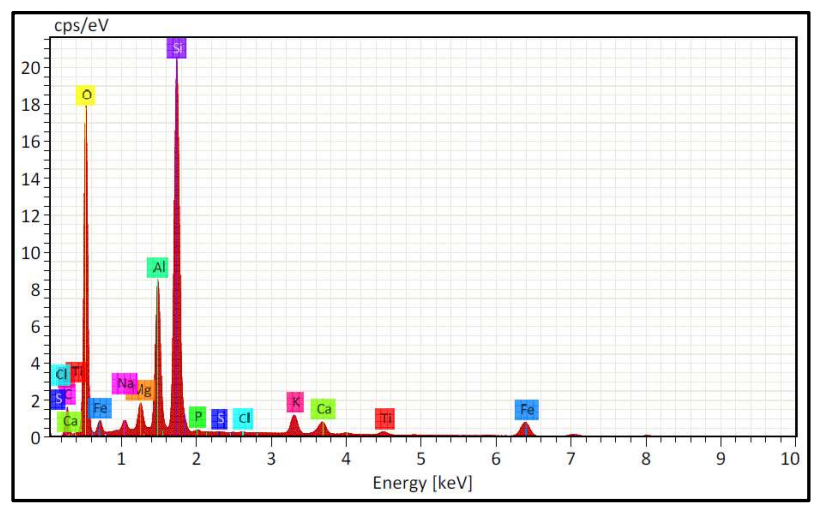

Figure 3. EDS spectrum showing chemical elemental distribution of fine particles sample. 